\title{
The contribution of nutrients from parent material in three deeply weathered soils of Peninsular Malaysia
}

\begin{abstract}
Three deeply weathered soil profiles developed over basalt, granite and schist were studied. The isovolumetric calculation was carried out to determine the intensity of elements depleted during weathering. The rain and stream waters near the respective areas were sampled and analysed. Despite the differences in their parent materials, the physico-chemical properties of the soil proper were quite similar. The study generally indicated that the humid tropical rain forests developed over old, deeply weathered soils of Peninsular Malaysia have a ñclosedò nutrient cycling system because the contribution of nutrients from the weathering parent material is negligible. Closed nutrient cycles are favoured by intense weathering at great depth, and by the almost complete loss of bases during the rock-saprock-saprolite transformation. The chemical properties of the saprolites are found to be comparable to or even poorer than those of the subsoils, so that roots do not have access to the base cations released on initial weathering.
\end{abstract}

Keyword: Saprolite; Nutrient cycling; Weathering; Malaysia 